IdeAs

Idées d'Amériques

$3 \mid 2012$

L'alimentation dans les Amériques au prisme des sciences sociales

\title{
A alimentação: questões teóricas e empíricas nas Américas
}

Philippe Cardon e Domingo Garcia-Garza

\section{(2) OpenEdition}

Journals

Edição electrónica

URL: https://journals.openedition.org/ideas/3139

DOI: $10.4000 /$ ideas.3139

ISSN: 1950-5701

\section{Este artigo é uma tradução de:}

L'alimentation : enjeux théoriques et empiriques dans les Amériques - URL : https:// journals.openedition.org/ideas/403 [fr]

Outra(s) tradução(ões) deste artigo:

Theoretical and empirical aspects to food in North and South America - URL : https:// journals.openedition.org/ideas/2293 [en]

La alimentación: cuestiones teóricas y empíricas en las Américas - URL : https://

journals.openedition.org/ideas/2294 [es]

\section{Editora}

Institut des Amériques

\section{Refêrencia eletrónica}

Philippe Cardon e Domingo Garcia-Garza, «A alimentação: questões teóricas e empíricas nas

Américas», IdeAs [Online], 3 | 2012, posto online no dia 30 agosto 2018, consultado o 18 outubro 2022. URL: http://journals.openedition.org/ideas/3139 ; DOI: https://doi.org/10.4000/ideas.3139

Este documento foi criado de forma automática no dia 18 outubro 2022.

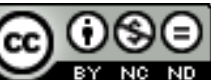

Creative Commons - Atribuição-NãoComercial-SemDerivações 4.0 Internacional - CC BY-NC-ND 4.0 https://creativecommons.org/licenses/by-nc-nd/4.0/ 


\title{
A alimentação: questões teóricas e empíricas nas Américas
}

\author{
Philippe Cardon e Domingo Garcia-Garza
}

1 A alimentação foi um motivo de interesse apenas marginal nos estudos sobre as sociedades da América do Sul, ao passo que nos Estados Unidos e no Canadá, a pesquisa sobre a alimentação experimentou, como na Europa, um maior desenvolvimento. Este terceiro número temático da revista IdeAs tem como objetivo preencher essa lacuna e relançar uma reflexão há muito tempo esquecida ou negligenciada pelas ciências sociais, mas sempre presente tanto na imaginação quanto no senso comum, nos dois lados do Atlântico. $O$ outro objetivo desta matéria é trazer uma nova perspectiva sobre a alimentação a nível continental, em uma perspectiva sociológica, antropológica e histórica.

2 "Fato social total", a alimentação oferece um ângulo privilegiado para estudar as sociedades. $\mathrm{O}$ historiadores e antropólogos estão entre os primeiros a se interessar por esse tema. Do lado europeu, as obras de Claude Levi-Strauss (1964), Fernand Braudel (1967), bem como as de Jean-Louis Flandrin e Massimo Montanari (1996) abriram o caminho para projetos de pesquisa bem sucedidos. Do lado americano, os historiadores (Garnsey, 1999; Gabaccia, 1998; Bauer, 2001) e os antropólogos (Douglas, 1965; Goody, 1982; Mintz, 1996, Mintz e Dubois, 2002) tornaram-se referência na matéria. As pesquisas realizadas sobre a questão alimentar na América Latina, ou aquelas publicadas em espanhol e português, privilegiaram uma perspectiva histórica (Freyre, 1933 Cascudo 1983; Flores, 2003; Fernandez-Armesto, 2004; Magalhães, 2004; Bourgues et al ., 2009), antropológica (Vargas, 1993, Ortiz et al, 2004, Contreras e Gracia, 2005; Carrasco, 2007; Bertran, 2010) ou multidisciplinar (Oseguera de 2003 Longa Solis y Vargas, 2005). Estes estudos se debruçam antes de tudo sobre as dimensões folclóricas, simbólicas ou identitárias regionais da alimentação ou sobre as práticas de grupos minoritários (de Suremain e Katz, 2009).

3 Nesta terceira matéria temática da revista IdeAs sobre a alimentação nas sociedades americanas (os universos anglo-saxão e hispânico), as diferentes contribuições oferecem uma leitura sociológica, antropológica e histórica do fato alimentar. Em 
primeiro lugar, os artigos se focalizam na alimentação como um marcador de identidade, quer se trate da identidade dos diferentes grupos sociais, ou da identidade nacional ou nacionalista de países latinoamericanos e norteamericanos. Alguns desses estudos evidenciam questões relativas à distinção social, à invenção de uma "cultura alimentar" ou ainda à "fabricação" de uma alimentação que faz parte de um discurso nacional, ou até mesmo nacionalista. Outros apontam para a produção e o consumo de alimentos locais, ou para as condições econômicas e sociais de sua comercialização tanto no plano local quanto no âmbito internacional. Além disso, há contribuições que analisam o papel da difusão de produtos alimentares, em diferentes países, sobre as práticas de alimentação dos migrantes, especialmente os migrantes que vão do sul para o norte, essa análise permitindo abrir um debate sobre o processo de "mistura" que caracteiza as cozinhas latinoamericanas. Nessa ótica, se a alimentação continua a ser um marcador de identidade forte (de classe, mas também nacional), ela também desempenha um papel no processo de "hibridização" das práticas, especialmente no contexto de migração. Assim, a questão da disseminação de estilos, formas e normas alimentares atravessa implicitamente todos os textos, quer se trate da difusão de novos padrões gastronômicos entre as elites brasileiras (Carolina Pulici), quer de novas normas alimentares "éticas" no Canadá, com diferentes populações (Josée Johnston et al.), ou de um item de luxo para uma população inteira (Natalia Milanesio), de práticas populares para as classes favorecidas (Garcia-Garza), do modelo crioulo na Argentina, em Cuba e no México (Jeffrey Pilcher), de práticas alimentares "híbridas" entre os Estados Unidos e os países da América do Sul (Maximino Matus), ou quer ainda de práticas americanas entre os migrantes mexicanos (Frida Calderon-Bony). Isso levanta paralelamente a questão das condições sociais de apropriação destes novos estilos de alimentos. Um dos desafios deste dossiê temático é, portanto, perguntar-se até que ponto as sociologias da alimentação, que se desenvolveram muito na França (Poulain, 2001, 2002, 2012; Raven, 2000; Poulain e Raven, 2002; Regnier et al. 2006 Fischler e Masson, 2007), podem ser transpostas para as sociedades do continente americano.

\section{A alimentação como um fator de diferenciação social}

4 Muitos estudos destacam o fato de que a alimentação é um marcador social, quer se trate de trabalhos sobre o peso dos gastos alimentares no padrão de vida no México (Martinez e Villezca, 2003; Torres e Trápaga 2001), quer do papel da venda de certos tipos de alimentos como atividade econômica que permite evitar a exclusão social nos países "em desenvolvimento" (Babb, 1987; Tinker, 1997; Chaves, 2006; Garcia-Garza, 2009). Estes trabalhos inserem-se, de maneira geral, na problemática das diferenciações sociais dos consumos, o que também é bem conhecido nas obras europeias, especialmente na sociologia francesa (Herpin e Verger, 2008), desde os primeiros estudos de Maurice Halbwachs sobre o consumo dos operários e logo com os estudos de seus herdeiros, Pierre Bourdieu e Claude Grignon, entre outros. Eles demonstraram decisivamente a importância da diversidade social do consumo de alimentos que, para além de alguns pratos ou de conhecimentos culinários nacionais e patrimoniais, continuam a ser caracterizados por efeitos estruturais que dependem do grupo social (Grignon e Grignon, 1980 Regnier et al, 2006), da idade e do ciclo de vida (Cardon, 2010, 2009a, 2009b; Gojard e Cardon, 2009; Gojard, 2010) ou até mesmo da região (Poulain, 2001). Além disso, o surgimento de uma nova fonte alimentar, ligada ao desenvolvimento da indústria de alimentos, dos supermercados, do conceito de "fast 
food" e de novos produtos (congelados, por exemplo), não contestou a conservação de algumas "culturas alimentares locais" (Poulain, 2002). Assim, a alimentação segue constituindo um forte marcador social, através das práticas de certos grupos sociais.

\section{As questões em torno da distinção social}

5 O estudo da estrutura social do consumo, naturalmente, conduz a uma análise dos mecanismos da distinção, tal como foi estudada por Pierre Bourdieu, especialmente em sua principal obra, $L a$ distinction (1979), em que ele defende a tese segundo a qual a posição social, dentro do espaço social, determina um estilo de vida e, por extensão, determinados gostos, em particulars gostos alimentares, que são socialmente marcados (Bourdieu, 1976). Os gostos sendo "classificadores", na medida em que são suportes de classificação, também são marcadores da posição social no espaço social. Neste número, Johnston, Szabo e Rodney, assim como Garcia-Garza, evidenciam que as características sociais exercem uma influência significativa no consumo de alimentos. Johnston et al. Mostram, por exemplo, como se constrói uma alimentação "ética" no Canadá, a partir da observação de dois grupos sociais distintos (classes populares contra as classes favorecidas). Esses autores enfatizam o papel do capital cultural, além do contexto social, na motivação dos consumidores para comprar produtos considerados "orgânicos" ou ambientalmente amigáveis e saudáveis. Por sua vez, Garcia-Garza destaca como o processo de enobrecimento de produtos populares ajudou a redefinir a legitimidade da hierarquia alimentar no México.

6 Além disso, vários textos, neste número, fazem a demonstraçã de que novos estilos de alimentação não fazem necessariamente desaparecer as diferenças sociais ou relações simbólicas entre as classes. Na verdade, os novos hábitos alimentares, tanto quanto antes, traçam fronteiras simbólicas entre os diferentes grupos sociais (Bourdieu, 1979; Cole, 2008). Lamont (1992), por exemplo, aponta o fato de que as fronteiras classificadas em três categorias (socioeconômica, cultural, moral) podem incluir ou excluir membros de uma sociedade de acordo com o seu estatuto, a posse de recursos, os seus avanços sociais. Ela assinala a correlação dos estilos de vida com os diferentes estatutos sociais. Este aspecto já foi levantado por Bourdieu (1979), quando ele estudou a dimensão cultural das práticas de diferenciação social.

7 Em todos os casos, a manutenção das diferenciações sociais, independentemente da difusão de novos estilos alimentares em ambos os lados da escala social, relança o debate sobre o onivorismo cultural (Peterson, 1992; Peterson e Kern, 1996; Duval, 2010; Coulangeon, 2011). Como qualquer outra prática cultural, a alimentação obedece aos jogos de diferenciação social a partir das posições dos indivíduos e dos grupos no espaço social, sobretudo em função do nível de educação e das origens socioculturais. As práticas culturais, nesse sentido, correspondem com diferentes classes sociais. O comportamento onívoro é observado apenas em grupos favorecidos, e quando eles têm uma cultura de "ecletismo informado", ou seja, uma diversificação cultural seletiva (Donnat 1994; Eloy e Paletta, 2008; Eloy, 2012). Em outras palavras, as práticas culturais associadas a um comportamento eclético estão presentes apenas nos grupos sociais privilegiados. Além disso, essas práticas ocorrem apenas ocasionalmente, já que os grupos sociais favorecidos preferem práticas culturais próprias a seu meio de origem. Além disso, como Johnston e Bauman (2007: 198) o apontam, Bourdieu já tinha percebido a emergência de uma tendência ao onivorismo para os indivíduos que têm 
mais capital cultural do que capital econômico (os professores, no caso do estudo referido), e que, portanto, têm consumos ascéticos e buscam o "exótico" e o "populismo culinário" (Bourdieu, 1979: 207). A partir de diferentes contribuições para esta revista IdeAs, podemos medir a força e a validade da teoria da legitimidade cultural delineada por Bourdieu no final de 1970.

\section{A apropriação de novos modelos alimentares}

8 Uma das questões teóricas deste número da IdeAs é, portanto, levar em conta a apropriação social de novos modelos alimentares, quer se trate de novas gastronomias, como Carolina Pulici o propõe em seu estudo das elites brasileiras (banqueiros, embaixadores, colecionadores de arte, pensionistas, industriais, empresários) ou de uma alimentação ética estudada por Josée Johnston e seus colegas, no Canadá. Estes autores procuram entender como e em que condições sociais estes novos modelos tornam-se ou não suportes de distinção social. Caroline Pulici se esforça em analisar (retomando uma metodologia de pesquisa iniciada por Norbert Elias, em sua obra La Civilisation des mœurs) manuais de etiqueta publicados recentemente no Brasil e críticas gastronômicas publicadas na imprensa paulista entre 2005 e 2009, a fim de melhor identificar determinados padrões que aparecem como legítimos hoje, em termos de culinária e de boas maneiras à mesa. A autora analisa de que maneira as elites estão recuperando ou não esses novos padrões alimentares paran formar representações sociais de si mesmas e em relação com outros grupos sociais, e como esses novos modelos de alimentação permitem às elites situarem-se socialmente em comparação com outras, especialmente as classes populares. Assim, em oposição com uma alimentação popular que as elites consideram como "voraz" (a "ganância popular" seria a expressão dos sentimentos naturais), eles desenvolveram uma cultura alimentar que rejeita justamente estes traços de percepção próprios às classes populares. Esta censura dos sentimentos naturais funciona como regra de controle alimentar, de moderação e de senso estético que então caracterizam um estilo burguês em relação à alimentação. A apropriação dessa nova cozinha gastronômica mantém a distinção social; participa do desenvolvimento de uma representação e de uma ética baseadas no autocontrole. A autora, que recicla a própria tese do autocontrole desenvolvido por Norbert Elias sobre as sociedades europeias, escreve: "Enquanto o 'povo', que tem menos a esperar do futuro, se perde nos sensualismos, a elite comprovaria o autodomínio em todas as direções, ou seja, no controle de seus apetites corporais, mas também de suas condições ideais e materiais de existência ". Aqui, a alimentação, já que está ligada a uma ética de vida específica a um grupo, permite manter e inclusive marcar a distância com outros grupos sociais, diferenciando-se deles. Agora entendemos como esses novos padrões gastronômicos são apropriados com tanta ânsia pela elite brasileira, na medida em que funcionam como um repertório simbólico para distinguir-se de outros grupos sociais.

9 No entanto, o que distingue a priori sempre levaria uma diferneciação concreta? Esta é a pergunta em torno da qual se articula o artigo de Josée Johnston et al, sobre a disseminação da chamada alimentação "ética" na sociedade canadense. Esse padrão alimentar é altamente valorizado pelo governo, uma vez que representa um novo mercado e que potencialmente pode constituir algum tipo de ganho em termos de saúde. Com base em uma pesquisa qualitativa ( 40 famílias), as autoras procuram ver se a alimentação ética, que normalmente aparece a partir de práticas culturais específicas 
às classes privilegiadas, também pode atingir outros grupos sociais, incluindo as classes populares. Em outras palavras, elas procuram determinar como o discurso sobre a ética alimentar é percebido e praticado por todos os consumidores que não desfrutam dos mesmos privilégios. Elas distinguem duas fases em sua análise. Por um lado, elas procuram ver se há ou não diferenças de classe na maneira de apreender simbolicamente a ética alimentar, e se isso faz algum sentido para as pessoas de grupos sociais não favorecidos. Elas examinam como os discursos sociais modelam as práticas alimentares. Para isso, elas recorrem, em primeiro lugar, ao conceito de "repertório cultural" (Lamont, 1992; Tilly, 1993; Swidler 1986, 2001), emprestado da sociologia da cultura (elas desenvolvem o conceito de "repertório da alimentação ética"), que permite perceber a forma "criativa com que os atores usam diariamente elementos selecionados do discurso" sobre a ética. Elas, num segundo momento, mobilizam o conceito de "fronteiras simbólicas", que leva as pessoas a traçar limites para distinguirse dos outros e também significar sua presença dentro de um grupo - tudo isso na continuidade dos trabalhos de Durkheim e Mauss (1903), Becker (1963), Douglas (1966). A partir do estudo de discursos de indivíduos de diferentes origens sociais, estes dois conceitos permitem-lhes mostrar que o privilégio econômico e cultural favorece um acesso ao reportório dominante da alimentação ética, uma vez que pessoas de origens sociodemográficas e éticas populares ou marginalizadas têm menos acesso a este repertório. São, antes de tudo, pessoas brancas das classes médias que investem mais no repertório da alimentação ética. No entanto, num segundo momento, o estudo das práticas cotidianas em torno da alimentação revela que podem existir diferenças entre, por um lado, o reconhecimento de um discurso ético legítimo sobre alimentação e, por outro, a prática. Os privilégios culturais e econômicos certamente permitem o acesso ao repertório principal, mas "eles não garantem um alto grau de envolvimento" na prática.Para um grande número de pessoas de origens privilegiadas, independentemente de estarem ou não envolvidas na alimentação ética, são sobretudo comportamentos alimentares considerados como "saudáveis que cumprem a função de marcador social, constituindo um fator de diferenciação cultural. Ao contrário, o fato de que os grupos marginalizados estão menos envolvidos na alimentação ética não significa que "eles não se sentem preocupados com os dilemas morais das escolhas alimentares." Para os autores, este resultado é central porque confirma os trabalhos que refutam a tese da falha moral das classes trabalhadoras, segundo a qual estas últimas não conheceriam os problemas morais relacionados à alimentação ou não se importariam com isso (Johnston, Szabo e Rodney).

\section{A alimentação como um fator de identidade nacional ou nacionalista}

10 Embora alguns gostos alimentares permanecem fortes marcadores sociais que diferenciam as classes, outros adquirem o status de "patrimônio nacional", de bem comum, tornando-se emblemas de marcas culturais que transcendem as distinções de classe. Desta forma, pode-se estudar a alimentação como um vetor de identidade (Pilcher, 1998; Thiesse, 1999; Lauriaux e Bruegel, 2002). Como a investigação europeia (Poulain, 1997, 2000, 2005; Espeitx 2008; Bessière e Tibério, 2010), alguns pesquisadores, do outro lado do Atlântico, observaram a patrimonialização da culinária latinoamericana, as práticas alimentares consideradas como "patrimônio cultural" e 
que encarnam a identidade nacional (Florescano 1993; Álvarez, 2002; Cottom, 2004, 2007, Álvarez y Medina, 2008; Moncusí e Santamarina, 2008; Zapata, 2008), embora a pesquisa neste domínio ainda esteja, na América Latina, em estado embrionário (BakGeller e Katz, 2011).

11 A celebração do bicentenário da independência latinoamericana foi uma excelente oportunidade para refletir sobre o lugar ocupado pela alimentação nas sociedades sulamericanas. Nesta ocasião, vimos celebrar os pratos nacionais de diferentes países. Mas poucos estudos foram suficientes para ver como estes pratos contribuem para definir com precisão a identidade nacional dos países latinoamericanos no início do século XXI. No entanto, é interessante verificar que a identidade nacional é construída tendo em conta o passado e, em maior extensão, em comparação com o exterior. De norte a sul, as diferentes formas de alimentação para definir as culinárias nacionais mantêm uma relação particular com a cozinha internacional, podendo-ser uma relação de rejeito ou de atração. 0 México, por exemplo, continua a usar seu passado pré-colombiano para construir a "cozinha mexicana", mesmo que esta última não tenha realmente existido antes do século XX, uma vez que nasceu da fusão de várias técnicas e de vários elementos exógenos e endógenos (Pilcher, 1998). Em contraste, a Argentina rejeita o passado e se define apenas por laços muito fortes com outros países, obviamente devido às migrações europeias recentes. Isso se traduz por um certo cosmopolitismo da cozinha argentina (Pilcher, 2012), pelo menos na região conhecida como La Pampa (Milanesio).

\section{A difusão de cima para baixo...}

12 Em alguns casos, o bem comum nacional, ou patrimonial por meio de uma construção social, torna-se o suporte e a ferramenta de uma propaganda nacionalista, com uma finalidade de propaganda política. A alimentação pode ser usada para reunir um povo, quando é elevada ao status de emblema nacional, servindo para uma política ideológica forte de cunho nacionalista. É o que destaca Natalia Milanesio em seu estudo sobre o papel da produção e do consumo de carne bovina na propaganda "peronista" (palavra que deriva do nome do ex-presidente argentino Juan Domingo Perón). Na sua análise dos aspectos estruturais e institucionais característicos da política alimentar peronista de 1950, a estudiosa mobiliza o conceito de "virtuosismo semiótico" da alimentação, desenvolvido pelo antropólogo Arjun Appadurai (1988), e que designa a capacidade do signo cultural de poder transmitir várias mensagens. Assim, ela tenta delinear os usos ideológicos que o Estado faz do consumo de alimentos, e revela em particular as implicações simbólicas do consumo de carne bovina na política alimentar do Estado. Como ela aponta em conclusão, "a política bovina do peronismo antes de 1950 ultrapass[a] o simples aumento do consumo per capita: ela redefine a imagem da Argentina na economia global, torna válido o conceito de autodeterminação econômica e permite corroer, pelo menos no nível do discurso, o papel do capitalismo internacional". Tradicionalmente considerado como um alimento de luxo, a carne devia ser o símbolo de acesso das classes populares a novos bens e, portanto, de um novo lugar na sociedade. A política peronista ajudou a difundir o consumo de carne para fins políticos: preferir os consumidores nacionais aos mercados estrangeiros para promover a difusão de uma ideologia poderosa de soberania econômica via política bovina. Além das questões políticas e eleitorais (algumas das quais estão associadas com o 
populismo), fazer do boi um emblema nacional serviu para redefinir os papéis tradicionais masculino e feminino: "tradicionalmente cozinhados pelas mulheres, os pratos recomendados pelo governo peronista reafirmaram o papel fundamental das mulheres na construção da identidade culinária nacional, num discurso que se distancia da figura dohomem cozinheiro". Porque tradicionalmente homens apenas se envolveriam na cozinha para a preparação de carne grelhada.

Através deste exemplo, entendemos melhor como a difusão vertical, para as classes populares, de certos pratos que são marcadores indiscutíveis da classe social pois costumam ser reservados para a elite, permitia dar vigor a uma política nacionalista. No entanto, a questão da difusão de sabores é central na sociologia da alimentação, porque nos obriga a pensar o espaço e a diferenciação social de uma forma dinâmica e não congelada. Alguns grupos sociais emprestam a outros grupos algumas de suas características. Por vezes, em nome de um princípio político, como vimos no exemplo da política peronista, certos grupos trabalham para difundir o seu modelo alimentar. Mas a difusão dos modelos e das preferências alimentares também transcende as fronteiras simbólicas entre as classes (Milanesio; Garcia-Garza; Pilcher; Johnston e Bauman, 2010) e, portanto, a alimentação é longe de ser um assunto insignificante, e ainda mais longe de ser algo politicamente neutro. A partir do momento em que a alimentação se aplica a todos os indivíduos e que o Estado é responsável por garantir as condições de acesso e garantir certa qualidade (Stanziani, 2005) para preservar a saúde da população, ela torna-se uma questão política.

\section{...e a difusão de baixo para cima}

14 No entanto, esta difusão vertical também ocorre de baixo para cima. Isto é o que Domingo Garcia-Garza demonstra em seu artigo sobre as práticas populares a partir do caso dos tacos (panquecas salgadas recheadas), na cidade de Monterrey, no México. Inicialmente visto como um produto popular, os tacos se espalharam por todo o espaço social a partir da década de 1990, adaptando-se aos gostos e aos padrões de consumo de várias camadas sociais, especialmente as mais ricas. Embora seu consumo seja generalizado em toda a sociedade, as variações que diferenciam os grupos sociais continuam. Garcia-Garza aponta para o fato de que este "emburguesamento" dos pratos e das práticas populares só foi possível à custo de uma valorização da qualidade e do preço do produto, assim como de uma recontextualização mais adequada para os cânones da restauração clássica. Isso foi levado a cabo porque a imagem dos tacos, assim revalorizada, ajudou a definir a identidade nacional. Mas é também devido ao fato de que estas práticas são relacionadas com o conceito de terra local e de autenticidade, com a utilização de produtos agora considerados como "gourmets": produtos anteriormente desvalorizados, os tacos de insetos, gafanhotos ou huitlacoche (fungo que cresce no milho, considerado como um equivalente do caviar no México) se tornaram hoje uma fonte de orgulho nacional e distinção social, principalmente para as elites. Tudo isso redefine a legitimidade de pratos populares e, portanto, a hierarquia dos alimentos no México. 


\section{Disseminação e metamorfoses dos gostos entre os países}

15 Se os casos estudados até agora levantavam, de maneira mais ou menos explicita, a questão da difusão e da circulação dos padrões alimentares entre os grupos sociais num contexto nacional, essa mesma questão surge ainda mais explicitamente no caso do movimento transfronteiriço de gêneros alimentícios. Isto foi o objeto de inúmeros debates na Europa e nos Estados Unidos, em particular sobre a distribuição dos modelos alimentares a nível mundial e sua apropriação ou não pelas culturas nacionais. Assim, a tese da "Mc-Donaldisação" da sociedade, desenvolvida no início da década de 1990 (Ritzer, 1993) e agora amplamente criticada, opõe-se a tese da "era da customização em massa" (Taylor, Smith e Lyon, 1998): a difusão de hábitos alimentares extranacionais requer alguma conformidade com os hábitos de consumo locais. Nesta perspectiva, é a dimensão nacional, ou seja, local, que serve como ponto de observação: o pesquisador tenta entender como os estilos alimentares extranacionais importados são apropriados ou não dentro do território nacional.

\section{O peso do contexto nacional na divulgação de modelos internacionais}

Uma dos pontos essenciais é entender como um espaço nacional administra tradições locais e nacionais em um contexto de forte difusão, a nível mundial, de práticas transnacionais. Esta questão da relação entre o local e o global é precisamente o tema do artigo de Jeffrey Pilcher em três países latinoamericanos (Argentina, Cuba e México). Numa perspectiva histórica, ele estuda as interações entre práticas locais e internacionais, e demostra como o local e o global estão intimamente entrelaçados; mas esse entrelaçamento varia de acordo com as circunstâncias nacionais. As práticas de culinária crioula (aquelas desenvolvidas nas novas repúblicas nascidas da fragmentação do Império espanhol), são mais ou menos afirmadas em função dos recursos disponíveis, da data da independência, das relações internacionais e, finalmente, das questões políticas de cada país. Comer "crioulo" é mais comum em Cuba e no México (embora o termo tenha sido banido do vocabulário), do que na Argentina.

Os trabalhos iniciados por Pilcher nos últimos dez anos, mais ou menos desconhecidos na França, indicam que as cozinhas e as identidades nacionais se definem conforme os principais estilos culinários consagrados em países que têm servido como sociedades de modelo para a América Latina (neste caso a França, a Espanha e a Inglaterra). Ele sugere que comer "à la criolla", significa, no fundo, adaptar pratos europeus com ingredientes locais disponíveis e estados de espírito próprios ao local. Mas isso não ocorre da mesma forma ou com os mesmos ingredientes. Até porque a relação que os três países observados mantêm com os antigos impérios coloniais não é a mesma de um país para o outro. $O$ interesse de uma abordagem comparativa entre as diferentes nações vem do fato de que os mecanismos de difusão e de integração de novos alimentos, pratos e estilos de comida, do global ao local, devem ser analisados no contexto nacional e com uma atenção à permanência de certas condições locais. $O$ autor nos permite entender a maneira pela qual as três tradições culinárias, longe de se opor à globalização, combinam tanto com o patriotismo quanto com o cosmopolitismo, criando as novas 
cozinhas nacionais ou crioulas. As cozinhas do México, de Cuba e da Argentina são emblemáticas, cada uma à sua maneira, do processo de sincretismo culinário, que ocorreu no final do século XIX. Estudando o modelo de difusão crioulo na literatura e nas práticas culinárias na Argentina, em Cuba e no México, Pilcher estabelece a relação entre esses dois níveis. Ao passo que, em Cuba, o termo criollo passou a incluir a comida local em torno da categoria de viandas (tubérculos como a mandioca, batata, batata doce, etc), na Argentina o termo criollo abrange uma quantidade maior de produtos locais (como por exemplo, as empanadas latinoamericanos, os pucheros com sopas squash e os milhos indígenas). Por outro lado, o México não incorporou realmente o termo criollo(a). Este paísz desenvolveu estas mesmas práticas culinárias que ele adaptou ao clima político da época e aos gostos locais. A cozinha criolla, na verdade, sempre existiu no México. Mas ela não recebe esta denominação porque a palavra criolla manteve seu antigo significado (ou seja, os espanhóis nascidos no México), muito conotado e, portanto, mal aceito pelos mexicanos fortemente imbuídos de nacionalismo. Consequentemente, o México evacuou a questão da origem e da influência espanholas na comida mexicana, eliminando as palavras para se referir a isto. As elites mexicanas, que em sua maioria são de origem europeia, se autoproclamam herdeiras dos astecas e de seu património culinário. Elas afirmam um orgulho da culinária mexicana pré-colombiana e de suas fontes, apesar de excluir e de marginalizar os povos indígenas na sociedade contemporânea. Portanto, elas se apropriaram do passado indígena para forjar uma cozinha nacional e convidar-se para o processo de ocidentalização. É como se tivesse sido necessário livrar-se da origem estrangeira das práticas culinárias para forjar um caráter nacional. De qualquer forma, esta é uma maneira de apagar um (doloroso) passado para inventar um presente mais conforme com os ideais nacionalistas nascidos depois da Revolução (1910-1920).

\section{A alimentação frente à migração}

18 A esta perspectiva sócio-histórica podem se associar abordagens mais etnográficas que se concentram em analisar os mecanismos de circulação dos bens alimentares na migração entre os países, particularmente dos países da América Latina em direção aos Estados Unidos. Uma das questões mais importantes é a de saber em quais condições sociais os migrantes da América do Sul, que vão para os Estados Unidos, mantêm os hábitos alimentares de seu país de origem ou desenvolvem outros. Não se trata apenas de decifrar como os modelos extraterritoriais são apropriados num país, mas também de compreender como e em que condições os hábitos locais se perenizam em uma lógica de mobilidade internacional. Vários elementos de resposta podem ser apresentados.

19 Um dos primeiros elementos de resposta radica precisamente no que está em jogo, do ponto de vista da identidade, na circulação dos bens alimentares. Nos exemplos apresentados por dois artigos da nossa revista, o alimento desempenha uma "força de lembrete de identidade" que de alguma forma transcende o alimento em si. Assim, no seu texto, Maximino Matus questiona as estratégias empregadas por grupos de varejistas e comerciantes afim de fazer circular clandestinamente alimentos entre os Estados Unidos e vários países da América Latina (e vice-versa), com o objetivo de satisfazer e atender à "nostalgia de um migrante por el sabor, olor y textura de um alimento". Por certo, é comum, nos Estados Unidos, encontrar varejistas e restaurantes 
que vendem produtos e alimentos de países latinoamericanos, ou seja, os países de origem dos imigrantes, mas é também frequente encontrar, nestes países, comerciantes e restaurantes que vendem produtos de vários países do planeta. Matus propõe então desenhar o que ele chama de "paisagens alimentares híbridos": em sua opinião, a diversidade das formas de migração dentro dos países da América Latina, e também entre a América Latina e os Estados Unidos, faz emergir hibridizações das práticas alimentares que afetam os migrantes, não só nos países de destino, mas também no país de origem. 0 exemplo da cidade de Oxcutzcab, no sudeste do México, é significativo: lá encontramos restaurantes asiáticos, italianos, franceses e norteamericanos. Segundo o autor, o desenvolvimento dessas ofertas alimentares "híbridas" faz parte de um pedido dos migrantes, vinculado à uma certa nostalgia de hábitos alimentares novos desenvolvidos durante a migração, incluindo os Estados Unidos. Isto é precisamente o que Calderón-Bony estuda: a nostalgia de hábitos alimentares, criados por imigrantes que vivem nos Estados Unidos e que são originários da comunidade de Patamban no México. Em seu trabalho, ela procura entender qual é o papel da alimentação na dinâmica de identidade associada à migração. Ela enfatiza, mais uma vez, o fato de que os migrantes são fortemente ligados a certos hábitos alimentares. Os itens alimentares tornam-se então bens que circulam entre seu país de origem e seu novo país anfitrião (no sentido contrário de outros bens que eles enviam para suas famílias em seus países de origem). Ora, uma das observações empíricas feitas pela autora é que esse apego pelos migrantes para determinados pratos relacionados com sua origem vem de uma razão simples: a nostalgia (Camou, 1994; Pilcher, 2012).

Um segundo elemento de resposta está relacionado com o fato de que se desenvolve uma "oferta" de alimentos do país de origem e dos mercados de produtos alimentares vindos dos países do Sul para os Estados Unidos. A este respeito, Calderón-Bony analisa o "mercado da nostalgia", apoiando-se no estudo de Hirai (2009) sobre o contexto da migração mexicana para os Estados Unidos. 0 "mercado da nostalgia" é um conceito a partir do qual "o migrante procura definir a relação entre a abertura de um comércio com produtos mexicanos como atividade econômica realizada por migrantes e o fornecimento de produtos que servem de identificação à cultura mexicana", quer se trate de mercadinhos (dedicados exclusivamente à venda de produtos comestíveis, como latas de diferentes tipos de pimentas, sementes de milho para preparar Pozole, tortillas e tostadas, folhas de milho para a preparação de tamales, queijo fresco) ou de lojas mais importantes que se aparentam mais a supermercados. A migração se torna então o suporte da emergência de uma nova oferta de alimentos no país em que se instalam os migrantes mexicanos. Mathus faz a mesma observação, mas mostra que, paralelamente a esta oferta, se desenvolvem os "mercados negros". De fato, enquanto a circulação dos alimentos não tem entraves entre países do Sul para abastecer um mercado de alta demanda, a circulação de produtos para os Estados Unidos é mais complicada, já que há fortes restrições sanitárias impostas aos produtos que entram na América. Na medida em que a demanda por alimentos dos países de origem dos migrantes é grande, o autor pergunta como os atores (incluindo os comerciantes) podem superar o que ele chama de "políticas persecutórias" norteamericanas, que buscam excluir determinados produtos de seu continente. Ele indica portanto a emergência de um mercado negro para certos produtos alimentares (por exemplo, de Oaxaca em Los Angeles, passando por Tijuana). 0 desenvolvimento desses mercados ilegais parece satisfazer, em parte, as demandas alimentares nostálgicas de migrantes. 
21 No entanto, o fato de encontrar lojas no local não impede que os migrantes tambémn recebam alimentos de suas famílias que ficaram em casa. Assim, além do desenvolvimento de mercados, oficiais ou nem tanto, há uma circulação de bens que podemos descrever como "privada", e que radica nas redes familiares. Calderón-Bony o demonstra perfeitamente no caso da circulação de bens alimentares. A autora insiste no fato de que o alimento circula no sentido oposto (do país de origem para o país anfitrião) de outros bens, tais como o dinheiro (do país anfitrião ao país de origem). Por outro lado, como ela mesma o afirma, "a circulação do alimento entre a aldeia e os Estados Unidos permite alimentar proximidades afetivas, consolidando os laços (familiares e amigáveis) e fazendo com que, aos mesmo tempo, esses alimentos ajudem a "digerir" as distâncias". Eis um ponto central, porque, basicamente, reencontramos a ideia do mana de Marcel Mauss (1924), que destacou o fato de que, numa troca, junto com a coisa circula o "espírito da coisa." É também por esta razão que podemos entender que o "prato daqui" nunca é o mesmo que o "de lá". Porque o que circula, mais do que o alimento, é o espírito associado com a comida, o da família. Aqui, a troca mantém a união do migrante com seus compatriotas. Será que a nostalgia é o espírito da coisa, do mana? Ou ainda, em outras palavras: nós não comemos os alimentos porque temos nostalgia, mas nós sentimos saudade porque nós os comemos.

Por fim, o último elemento de resposta está relacionado ao fato de que novos hábitos são integrados a partir do território da migração, permitindo assim uma construção da identidade entre aqui e lá. Se essa perspectiva está presente de maneira mais ou menos implícita no texto de Mathus através do seu conceito de alimentação híbrida (que pressupõe a justaposição de modos de alimentação pela integração múltipla ligada ao percurso migratório), ela é central na análise do papel da alimentação no texto de Calderon-Bony. $\mathrm{Na}$ verdade, isso mostra que há também, para os migrantes entrevistados, apropriação da cultura alimentar americana. Não se trata de opor a "preservação" de hábitos relacionados ao país de origem e a "mudança" relacionada com o país anfitrião, mas de pensá-las dialetica e dinamicamente como suporte de um processo de identidade. A alimentação é um suporte de identidade na migração, pois permite ao mesmo tempo manter a ligação com o país de origem, a região, a aldeia, a família, e incorporar novos valores relacionados à cultura de acolhimento. $\mathrm{O}$ artigo não pretende revisitar a questão da integração / assimilação, mas o interesse do texto é de mostrar como a identidade é um processo dinâmico em que a alimentação está envolvida. Enfatizando a dimensão dinâmica do processo de identidade através da alimentação (com a integração de novos hábitos alimentares próprios ao país anfitrião), a autora interroga questão da difusão de padrões alimentares em uma sociedade. 0 interesse de seu trabalho é, portanto, integrar uma dimensão geracional na compreensão do processo de difusão de padrões alimentares norte-americanos nas famílias de migrantes. Calderón-Bony mostra também que são as crianças que são as operadoras e emissoras de novos hábitos alimentares que, em vez de competir com os padrões originais, vêm completá-los ou redefiní-los.

Em suma, todas as contribuições deste terceiro número dão uma ideia da proliferação de problemáticas e de interrogações que as ciências sociais levantam hoje no estudo da alimentação nas Américas. Elas enfatizam todo o interesse heurístico de questões teóricas e empíricas que contribuem para o diálogo e o intercâmbio entre as disciplinas, de um lado, e entre os países e continentes, por outro. Elas incentivam a seguir desenvolvendo o diálogo Norte / Sul com outros países, a partir de outros objetos de 
estudo como a mobilidade, a circulação e a migração, que estão no centro da história das sociedades humanas.

\section{BIBLIOGRAFIA}

ÁLVAREZ Marcelo, «El gusto es nuestro. Modelos alimentarios y políticas de patrimonialización », Catauro : Revista Cubana de Antropología, nº 5, 2002, pp. 61-78.

ÁLVAREZ Marcelo y MEDINA Francisco-Xavier (eds.), Identidades en el plato. El patrimonio cultural alimentario entre América y Europa, Barcelona, Icaria, 2008.

APPADURAI Arjun, « How to Make National Cuisine : Cookbooks in Contemporary India », Comparative Studies in Society and History, vol. 30, $\mathrm{n}^{\circ}$ 1, 1988, pp. 3-24.

BABB Florence, «From the Field to the Cooking Pot : Economic crisis and the threat to marketers in Peru », Ethnology, vol. 26, n. 2, 1987, pp. 137-49.

BAK-GELLER Sarah et KATZ Esther, "Semana de Estudios de Cocina y Alimentacion en América Latina », Guadalajara (México), Congreso Internacional : De los primeros recetarios nacionales a las cocinas patrimoniales. 200 años de nacionalismo culinario en América Latina, 12-15 sept., 2011.

BAUER Arnold, Good, Power, History. Latin America's Material Culture, Cambridge, Cambridge University Press, 2001.

BAUMAN Shyon and JOHNSTON Josée, «Democracy versus Distinction : A Study of Omnivorousness in Gourmet Food Writing ", American Journal of Sociology, vol. 13, n 1, 2007, pp. 165-204.

BECKER Howard, Outsiders : Studies in the Sociology of Deviance, New York, The Free Press, 1963.

BERTRAN Miriam, «Acercamiento antropológico de la alimentación y salud en México », Phycis : Revista de Saúde Coletiva, vol. 20, n² 2, 2010, pp. 387-411.

BESSIÈRE Jacinthe et TIBÈRE Laurence, « Éditorial : Patrimoines alimentaires », Anthropology of Food, $\mathrm{n}^{\circ} 8,15$ juin, 2010. Disponible en ligne : http://aof.revues.org/6782.

BOURDIEU Pierre, La distinction. Critique sociale du jugement, Paris, Minuit, 1979.

BOURDIEU Pierre et SAINT MARTIN (de) Monique, "Anatomie du goût », Actes de la recherche en sciences sociales, $\mathrm{n}^{\circ}$ 5, 1976, pp. 2-81.

BOURGUES Héctor, BENGOA José y O'DONNELL Alejandro (eds.), Historias de la Nutrición en América Latina, México, SLAN, 2009.

BRAUDEL Fernand, Civilisation matérielle, économie et capitalisme (XVe-XVIII ${ }^{e}$ siècles), Paris, Armand Colin, 1967.

BRUEGEL Martin et LAURIAUX Bruno (eds.), Histoire et identités alimentaires en Europe, Paris, Hachette, 2002.

CAMOU Ernesto, «La nostalgia del rancho : Notas sobre la cultura urbana y a la carne asada » in Shoko DOODE y Emma-Paulina PÉREZ (eds), Sociedad, economía y cultura alimentaria, Hermosillo, CIAD/CIESAS, 1994, pp. 421-429. 
CARDON Philippe, «Regard sociologique sur les pratiques alimentaires », Gérontologie et société, $\mathrm{n}^{\circ}$ 134, 2010, pp. 31-42.

CARDON Philippe, « Manger en vieillissant pose-t-il vraiment problème ? Veuvage et transformations de l'alimentation des personnes âgées ", Lien Social et Politiques, n 62, 2009a, pp. 85-95.

CARDON Philippe, «Retraite et alimentation : les effets de la mobilité », Recherches familiales, $n^{\circ} 6$, 2009b, pp. 105-115.

CARDON Philippe et GOJARD Séverine, « Les personnes âgées face à la dépendance culinaire : entre délégation et remplacement », Retraite et société, n 56, 2009, pp. 169-193.

CARRASCO Noelia, « Desarrollos de la antropología de la alimentación en América Latina : hacia el estudio de los problemas alimentarios contemporáneos », Estudios Sociales, vol. 16, n 30, 2007, pp. 79-102.

CASCUDO Luis da Camara, Historia da alimentaçao no Brasil, Sao Paulo, Universidade de Sao Paolo, 1983.

CHAVES Mônica, « La restauration hors foyer dans l'État brésilien de Minas Gerais », Journal des Anthropologues, $\mathrm{n}^{\circ}$ 106-107, 2006, pp. 189-204.

COLE Nicki, « Global capitalism organizing knowledge of race, gender and class : The case of socially responsible coffee ", Race, Gender and Class, vol. 15, n 1-2, pp. 170-187.

CONTRERAS Jesus y GRACIA Mabel, Antropología y Cultura. Perspectivas antropológicas, España, Ariel, 2005.

CORBEAU Jean-Pierre et POULAIN Jean-Pierre, Penser l'alimentation. Entre imaginaire et rationalité, Paris, Privat, 2002.

CORBEAU Jean-Pierre (coord.), Cuisine, alimentation, métissage, Paris, Bastidiana, 2000.

СОТТОМ Bolfy, « El patrimonio cultural como problema interdisciplinario », Red Patrimonio : Revista digital de estudios en patrimonio cultural, 2007a. Disponible en ligne : http:// engukuani.colmich.edu.mx/red/index.php?option=com_content\&task=view\&id=140\&Itemid=64. COTTOM Bolfy, « Diversidad y enfoques del patrimonio cultural », Cuadernos del Patrimonio Cultural y Turismo, $\mathrm{n}^{\circ} 8,2004$.

DONNAT Olivier et TOLILA Paul (eds.), Le(s) public(s) de la culture, Paris, Presses de Sciences Po, 2003.

DONNAT Olivier, Les français face à la culture. De l'exclusion à l'éclectisme, Paris, La Découverte, coll. « Textes à l'appui », 1994.

DOUGLAS Mary, « Les structures du culinaire », Communications, vol. 31, 1979, pp. 145-70.

DURKHEIM Émile et MAUSS Marcel, « De quelques formes primitives de classification. Contribution à l'étude des représentations collectives ", Anneé sociologique, n 6, 1903.

DUVAL Julien, « Distinction studies », Actes de la recherche en sciences sociales, $\mathrm{n}^{\circ} 181-182,2010$, pp. 146-156.

ELOY Florence et PALHETA Ugo, « Cultures juvéniles et enseignement musical au collège », Revue française de pédagogie, $\mathrm{n}^{\circ}$ 163, 01 juin, 2008. Disponible en ligne : http://rfp.revues.org/957.

ELOY Florence, Apprendre à écouter la musique. Culture légitime, culture scolaire et cultures juvéniles, Paris, EHESS, thèse, (dir. D. Pasquier), 2012. 
ESPEITX Elena, « Los sentidos del patrimonio alimentario en el sur de Europa » in Marcelo ALVAREZ y Francisco-Xavier MEDINA (eds.), Identidades en el plato. El patrimonio cultural alimentario entre Europa y América, Barcelona, Icaria, 2008, pp. 45-62.

FERNANDEZ-ARMESTO Felipe, A comida : uma historia, Rio de Janeiro, Record, 2004.

FISCHLER Claude et MASSON Estelle, Manger. Français, Européens et Américains face à l'alimentation, Paris, Odile Jacob, 2007.

FLANDRIN Jean-Louis et MONTANARI Massimo, Histoire de l'alimentation, Paris, Fayard, 1996.

FLORES Jesus, Breve historia de la comida mexicana, México, De Bolsillo, 2003.

FLORESCANO Enrique (coord.), El patrimonio cultural de México, México, FCE, 1993.

FREYRE Gilberto, Casa grande e senzala. Formação da familia brasileira sob o regime de economia patriarcal, Rio de Janeiro, Maia e Schmidt, 1933.

GABACCIA Donna, We are what we eat. Ethnic Food and the Making of the Americans, Boston, Harvard Univeristy Press, 1998.

GARNSEY Peter, Food and Society in Classical Antiquity, Cambridge, 1999.

GARCIA-GARZA Domingo, « Una etnografía económica de los tacos callejeros en México. El caso de Monterrey », Estudios Sociales, vol. 19, n 37, 2011, pp. 32-63.

GARCIA-GARZA Domingo, «Prácticas alimenticias y clasificación social. ¿Los tacos son un alimento 'popular' ?», Civitas, vol. 10, n 3, 2010, pp. 430-449.

GARCIA-GARZA Domingo, L'entreprenariat informel. Le cas des marchands de tacos à Monterrey (Mexique), Paris, EHESS, thèse, (dir. R. Lenoir), 2009.

GOJARD Séverine, Le métier de mère, Paris, La Dispute, coll. « Corps santé société », 2010.

GOODY Jack, Cooking, Cuisine and Class, London, Cambridge University Press, 1982.

GRIGNON Claude et GRIGNON Christine, "Styles d'alimentation et goûts populaires », Revue française de sociologie, 1980, vol. 21, pp. 531-569.

HERPIN Nicolas et VERGER Daniel, Consommation et modes de vie en France. Une approche économique et sociologique sur un demi-siècle, Paris, La Découverte coll. « Grands Repères ", 2008.

HIRAI Shinji, Economía política de la nostalgia : un estudio sobre la transformación del paisaje urbano en la migración transnacional entre México y Estados Unidos, México, UAM/Juan Pablo Editor, 2009.

LAMONT Michèle, Money, Morals, and Manners: The Culture of the French and the American UpperMiddle Class, Chicago, University of Chicago Press, 1992.

LEVI-STRASS Claude, Mythologiques, Paris, Plon, (4 volumes), 1964.

LONG-SOLIS Janet y VARGAS Luis, (eds.), Food Culture in Mexico, Westport/London, Greenwood Press, coll. « Food Culture Around the World », 2005.

MONCUSÍ Albert y SANTAMARINA Beatriz, « Bueno para comer, bueno para patrimonializar. La propuesta de la cocina mexicana como Patrimonio Inmaterial de la Humanidad » in Marcelo ÁLVAREZ y Francisco-Xavier MEDINA (eds.), Identidades en el plato. El patrimonio cultural alimentario entre América y Europa, Barcelona, Icaria, 2008, pp. 127-142.

MAGALHãES (de) Sônia M., A Mesa de Mariana : Produção e consumo de alimentos em Minas Gerais (1750-1850), São Paulo, Annablume/Fapesp, 2004. 
MARTINEZ Irma y VILLEZCA Pedro, « La alimentacion en México. Un estudio a partir de la encuesta nacional de ingresos y gastos de los hogares ", Notas : Revista de información y análisis (INEGI), 2003, pp. 26-37.

MINTZ Sidney, Tasting food, Tasting Freedom : Excursions into Eating, Culture, and the Past, Boston, Beacon Press, 1996.

MINTZ Sidney and DUBOIS Christine, "The Anthropology of Food and Eating ", Annual Review of Anthropology, n³1, 2002, pp. 99-119.

ORTIZ Ana Silvia, VÁZQUEZ Verónica y MONTES Margarita, « La alimentación en México. Enfoques y visión de futuro », Estudios Sociales, vol. 13, n² 25, 2005, pp. 8-34.

OSEGUERA David, « La comida. Lugar de encuentro entre disciplinas científicas », Estudios sobre las culturas contemporáneas, vol. 7, n 13, 2001, pp. 141-151.

PETERSON Richard, « Understanding audience segmentation : from elite and mass to omnivore and univore », Poetics, $n^{\circ} 32,1992$, p. 169-194.

PETERSON Roger et KERN R.M., « Changing highbrow taste : from snob to omnivore », American Sociological Review, vol. 61, n 5, 1996, pp. 900-907.

PILCHER Jeffrey M., ; Que vivan los tamales! Food and the Making of the Mexican Identity, Albuquerque, University of Mexico Press, 1998.

PILCHER Jeffrey M., Planet Taco : A Global History of Mexican Food, New York, Oxford University Press, 2012.

POULAIN Jean-Pierre (dir.), Dictionnaire des cultures alimentaires, Paris, PUF, 2012.

POULAIN Jean-Pierre, « French gastronomie, french gastronomies » in Dara GOLDSTEIN and Kathrin MERKELE (eds.), Culinary cultures of Europe. Identity, Diversity and Dialogue, Strasbourg, Council of Europe Publishing, 2005, pp. 157-170.

POULAIN Jean-Pierre, Sociologies de l'alimentation. Les mangeurs et l'espace social alimentaire, Paris, PUF, coll. «Sciences sociales et sociétés », 2002.

POULAIN Jean-Pierre, Manger aujourd'hui : attitudes normes et pratiques, Toulouse, Privat, 2001.

POULAIN Jean-Pierre, « Les patrimoines gastronomiques et leurs valorisations touristiques » in Rachid AMIROU et Philippe BACHIMON, Le tourisme local, une culture de l'exotisme, L'Harmattan, 2000, pp. 157-183.

POULAIN Jean-Pierre, « Le gout du terroir à l'heure de l'Europe », Ethnologie française, vol. 27, 1997, pp. 18-26.

RITZER George, The MacDonaldization of Society. An Investigation Into the Changing Character of Contemporary Social Life, London, Sage, 1993.

STANZIANI Alessandro, Histoire de la qualité alimentaire XIX ${ }^{e}-X X^{e}$ siècles, Paris, Seuil, coll. « Liber », 2005.

SUREMAIN (de) Charles-Édouard et KATZ Esther, « Modelos alimentarios y recomposiciones sociales en América Latina », Anthrolpology of Food, 20 déc., 2009. Disponible en ligne : http:// aof.revues.org/6432.

SWIDLER Ann, Talk of Love : How Culture Matters, Chicago, University of Chicago Press, 2001.

TAYLOR Stephen, SMITH Shenna and LYON Phil, « McDonalization and consumer choice in the future : an illusion or the next marketing Revolution? » in Mark ALFINO, John S. CAPUTO and 
Robert WYNYARD (eds.), Mcdonaldization Revisited. Critical Essays on Consumer Culture, Westport/ London, Prager Publishers, 1998, pp. 105-119.

THIESSE Anne-Marie, La création des identités nationales. Europe XVII ${ }^{e}-X^{e}$ siècles, Paris, Seuil, 1999.

TILLY Charles, «Contentious repertoire in Great Britain, 1758-1834 », Social Science History, vol. $17, \mathrm{n}^{\circ} 20$, pp. 253-280.

TINKER Irene, Street Food. Urban Food and Employment in Developing Countries, Oxford, Oxford University Press, 1997.

TORRES Felipe y TRAPAGA Yolanda (eds.), La alimentación de los Mexicanos en la alborada del tercer milenio, México, UNAM, 2001.

VARGAS Luis A., « Antropología y alimentación », Antropológicas, n 7, 1993, pp. 22-23.

ZAPATA Sergio, « Patrimonialización de la gastronomía peruana y planteamiento de un proyecto de desarrollo » in Marcelo ÁLVAREZ y Francisco-Xavier MEDINA (eds.), Identidades en el plato. El patrimonio cultural alimentario entre América y Europa, Barcelona, Icaria, 2008, pp. 153-174.

\section{AUTORES}

\section{PHILIPPE CARDON}

Maître de conférences en sociologie, Université Lille 3. Chercheur au laboratoire Ceries (laboratoire de recherche individus-épreuves et société) / Université Lille 3. Chercheur associé au laboratoire ALISS (Alimentation et sciences sociales)/INRA.Philippe.Cardon@ivry.inra.fr

\section{DOMINGO GARCIA-GARZA}

Maître de conférences en civilisation latino-américaine (Université Charles de Gaulle). Chercheur au CECILLE (Lille 3) et chercheur associé au CESSP (EHESS/Paris 1/CNRS).

domingo.garciagarza@univ-lille3.fr 